\title{
Multivariate Analysis of a Time Series EU ETS: Methods and Applications in Carbon Finance
}

http://doi.org/10.21272/fmir.3(1).18-29.2019

\section{Rachid Boutti}

Professor, President of the Chair UNESCO Sustainable Development, Founder of LaRGe Laboratory, Director of the CREMA Indexed International Journal and Expert at the CNRS, Agadir, Morocco

\section{Adil El Amri}

Professor, Member of MAD Laboratory, Higher School of Technology of Sidi Bennour, Coordinator of the Department: Management Technique, University of Chouaib Doukkali, El Jadida, Morocco

\section{Florence Rodhain}

Professor, Director of the MRM-SI Research Team, University Polytechnic School, University of Montpellier, Montpellier, France

\begin{abstract}
Climate Change (CC) is a major issue of our century. Controlling the constraints of Greenhouse Gas (GHG) emissions through transformation into opportunities (Wettestad and Skjaerseth, 2007), in an organization to increase industrial production, has become a necessity. The main reason for this adoption was the effectiveness of energy management and responsible linkages that are being developed to determine the issues and opportunities of carbon finance for organizations. This article is part of the 21 st Conference of the Parties 2015 (COP21) of the United Nations Framework Convention on Climate Change (UNFCCC) in France in Paris. In this regard, it is the ultimate opportunity to present an accurate diagnosis of GHG emissions quantification and a holistic review of Climate Change (CC) recommendations. This scientific contribution was, in fact, a natural extension of the 22nd Conference of the Parties (COP22) hosted by the Kingdom of Morocco in Marrakech in 2016. Indeed, COP21 and COP22 Are two crucial deadlines, since they must lead to a new international agreement on climate, applicable to all countries, with the objective of keeping global warming below $2{ }^{\circ} \mathrm{C}$. This article aims to analyze and study the performance of Carbon Finance in the EU Sustainable Finance Business Emissions Trading Scheme (EU ETS). We will develop our quantitative methodology for the econometric study of the EU Emissions Trading Scheme (EU ETS) for both phases [Phase I: 2005-2007 and Phase II: 2008-2012] (Alberola, Chevallier and Cheze, 2009). The increasing complexity of Climate Change (CC) challenges creates a systemic view of EU ETS companies and a macroeconomic framework for environmental issues. In this context, we will develop our quantitative methodology adopted for the econometric study of the EU Emissions Trading Scheme (EU ETS) for the two phases of the EU ETS [Phase I: 2005-2007 and Phase II: 2008 -2012]. In the same direction, this scientific research addresses the thrilling question: "What are the responsible issues and sustainable and sustainable opportunities for the adoption of carbon finance for EU ETS companies for the development of a" $2{ }^{\circ} \mathrm{C}$ ?", In order to facilitate climate decision-making and to limit $\mathrm{CO} 2$ emissions. The real challenge is to contain the increasing complexity of Climate Change (CC) in a way that is compatible with the warming scenario limited to $+2{ }^{\circ} \mathrm{C}$. The development of the EU ETS is the reticular example of this turning point.
\end{abstract}

Key words: Sustainable Development; Kyoto Protocol; Carbon Finance; Multivariate Analysis; EU ETS.

JEL Classification: G30, O16, Q01, Q51, Q54.

(C) The Authors, 2019. This article is published with open access at Sumy State University.

Cite as: Boutti R., Amri Ad. El., Rodhain F. (2019). Multivariate Analysis of a Time Series EU ETS: Methods and Applications in Carbon Finance. Financial Markets, Institutions and Risks, 3(1), 18-29. http://doi.org/10.21272/fmir.3(1).18-29.2019.

\section{Introduction}

The scientific community began to take an interest in Climate Change (CC) in the 1970s. There is now a broad consensus on the responsibility for human-induced greenhouse gas (GHG) emissions in since the end of the pre-industrial era. The international community has since agreed on the need to act quickly to reduce them in order to limit the scale of future climate change. According to the IPCC, global average temperature could rise from $1.1^{\circ} \mathrm{C}$ to $6.4{ }^{\circ} \mathrm{C}$ by the end of the century. Given the disruptions, the consensus of states reached 
Financial Markets, Institutions and Risks, Volume 3, Issue 1, 2019 ISSN (online) - 2521-1242 ISSN (print) - 2521-1250

in Copenhagen and Durban aims to limit the increase in the average temperature of the planet to two degrees compared to the pre-industrial levels. To stay under this limit, scientific experts believe that at least half of global greenhouse gas emissions must be halved by 2050 (Bunn and Fezzi, 2007). Global warming is increasingly seen by investors as a long-term risk factor that could have a negative impact on asset valuation (Alberola and Chevallier, 2009).

In this context, a set of approaches and methodologies have been defined in recent years to evaluate the contributions of different sources of greenhouse gas (GHG) emissions, to quantify $\mathrm{CO} 2$ emissions and to Progress reports for a Sustainable Development. This transitional path involves a reorientation of part of the amounts invested in the carbon intensive sectors to the low-carbon sectors (Broome, 1992).

To respond to the challenges of climate change, a major reorientation of these approaches and methodologies is primordial. These strategies generate a reallocation of $\mathrm{CO} 2$ emissions, enabling industrial companies to first make an objective assessment of their emissions and to shed light on the resulting priorities (given the carbon limits recommended). The EU ETS to better understand the risks associated with Climate Change (CC) and to identify financial development opportunities related to GHG emissions (Alberola, Chevallier, Cheze, 2008), thus presenting existing CO2 pricing practices (EUA) By means of the econometric analysis of the two phases of the EU ETS Our article is organized as follows:

Axis 1: Treatments of the determinants of $\mathrm{CO} 2$ prices (EUA);

Axis 2: Specification of the variables / concepts of the EU ETS econometric model;

Axis 3: Restitution, validation and interpretation of EU ETS results.

\section{The determinants of $\mathrm{CO} 2$ prices (UAE): fundamental analysis}

The CO2 prices within the framework of the EU ETS depend on several determinants (variable) ${ }^{1}$. « Since 1 January 2005, every tonne of carbon emitted into the atmosphere in Europe by about 10,600 energy intensive installations has a price. The EU ETS covers $46 \%$ of the CO2 emissions from industries in Europe and aims to help Member States achieve compliance with their commitments under the Kyoto Protocol during 20082012. While the international quota trading system allows for exchange between governments from 2008 , the EU ETS extends the exchange of quotas at the level of the firm $[\ldots]{ }^{2}{ }^{2}$

Following this principle, it can be asserted that the real objective of the EU ETS to offer incentives to industrial firms to reduce their $\mathrm{CO} 2$ emissions and thus encourage the adoption of low-carbon technologies, to develop Efficiency Energy (EE), Renewable Energies (Renewable Energies) and the low carbon economy (Capoor and Ambrosi, 2009). We give an overview of the regulations governing Carbon Finance (Bokenkamp, La Flash, Bachrach Wang, 2005).

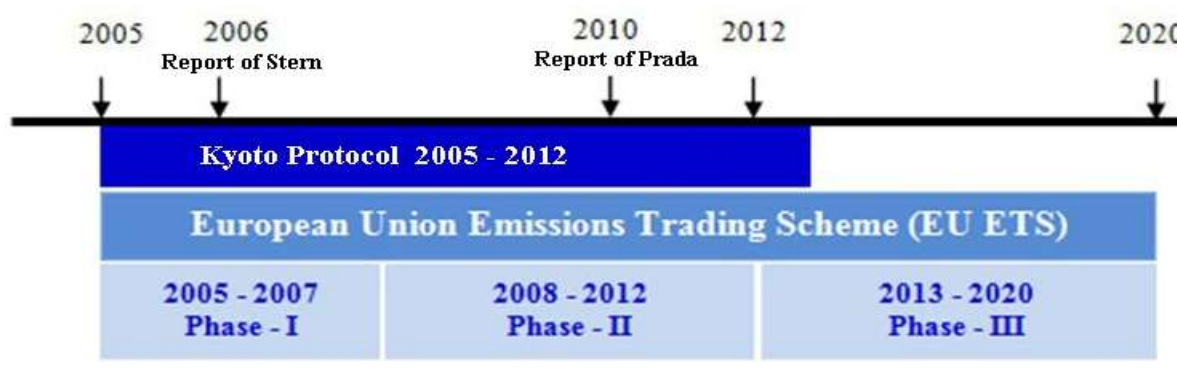

Figure 1. Overview of regulations governing carbon finance

Source: by authors.

The figure above highlights the three main phases of carbon finance. In 2006 (in Phase I), the Stern's report ${ }^{3}$ has established a prize concerned «The Environmental Threat of Climate Change (CC) ${ }^{4}$.

\footnotetext{
${ }^{1}$ The EU Emissions Trading System (EU ETS) is a market created by European Directive 2003/87 / EC.

${ }^{2}$ Translated. Chevallier, Julien. (2008). Les règles de fonctionnement du marché européen du carbone (2005-2007): le rôle du stockage et de l'emprunt de quotas, les fondamentaux du prix et les stratégies de gestion des risques ; 112 .

${ }^{3}$ Nicholas STERN, former chief economist at the World Bank. The "Stern Report", given to Tony BLAIR in October 2006, highlighted Climate Change in the economic sphere setting a price on the environmental threat.

${ }^{4}$ Morocco, organizer of COP 22 (Conference of the Parties "COP" to the United Nations Framework Convention on Climate Change "UNFCCC") after COP 21 in Paris this year 2015, hoped to be decisive in the major global negotiations on Climate Change (CC). Source: $\mathrm{http} / /$ www.usinenouvelle.com/article/le-commissaire-europeen-a-l-energie-en-visite-au-maroc-pour-parler-integration-regionale.N328289
} 
Financial Markets, Institutions and Risks, Volume 3, Issue 1, 2019

ISSN (online) - 2521-1242 ISSN (print) - 2521-1250

With this in mind, in 2010 (Phase II), the Prada's report created twenty-eight (28) technical recommendations for the correct regulation of carbon markets (Chevallier, 2012). « Most of them are already being pursued, either at Community level, in particular with the launch of Phase III of the European market [...] Their aim is to ensure the efficient functioning of these markets, and not to restrict its scope. Taken as a whole, they stress that the functioning of any market economy requires an appropriate institutional framework, hence the importance of this work» (Translated. Bureau, 2010).

Our study focuses on price changes in the EUA ${ }^{1}$, being the most liquid carbon asset. In this regard, we highlighted the daily spot price of the EUA to highlight the daily changes affecting this price, given the high volatility in this market (Bourgeois, 2010). Following this principle, we studied the determinants of CO2 prices (EUA), as follows:

- The first determinant: the price of carbon: price changes in the EUA;

- The second determinant: primary energy prices: oil, natural gas and coal;

- The third determinant: Clean Dark Spread, Clean Spark Spread and Switch Price;

- The fourth determinant: atmospheric variables;

- The fifth and determinant: SBF250 variations and the Subprime crisis.

In the next section, we will present our research hypotheses, the endogenous variable, the exogenous variables and the specification of the econometric model of the EU ETS.

\section{Specification of econometric model variables / concepts}

II. 1 Specification of modeling variables

We will highlight at this level the explained variable and the explanatory variables in our econometric work in order to test our first research hypothesis as follows:

General research hypothesis: The performance of the Carbon Finance Strategy for Sustainable Finance is based on the reaction of the fundamentals of quota prices of the European Union Emissions Trading Scheme (EU ETS).

In this regard, this general hypothesis of research suggests two adjacent under-hypotheses of research as follows:

- Adjacent research hypothesis n०1-1: The performance of the Carbon Finance Strategy for Sustainable Finance is influenced by the integration of information on $\mathrm{CO} 2$ emissions during Phase I of the EU ETS.

- Adjacent research hypothesis n'1-2: The performance of the Carbon Finance Strategy for Sustainable Finance is influenced by the Subprime crisis during the EU ETS Phase II.

\section{II.1.1 Specification of the variable to be explained (endogenous variable)}

This explained variable is measured by the change of spot EUA prices (Criqui and Kouvaritakis, 2000). The European Union Emissions Trading Scheme (EU ETS) can be used to express the yield from the carbon market allocation point of view (Delarue and D'haeseleet, 2007).

\section{II.1.2 Specification of explanatory variables (exogenous variables)}

At this level of analysis, our objective is to highlight the link between the performance of the strategies of the industrial players subject to the European Union Emissions Trading Scheme (EU ETS) for both periods via the variation of the spot price EUA and the Primary energy variables, atmospheric variables, CO2 emission information variables, fuel modification variables, structural movement variables and the subprime crisis variable).

\section{- The variables of the first period $2005-2007$}

The explanatory variables for the first test phase of the European Union Emissions Trading Scheme (EU ETS) are presented in four groups of explanatory variables. The group $[\mathbf{A}]$ contains the variables of primary energies namely Var.01: Variation of Brent price, Var.02: Variation of Gas price and Var.03: Variation of the price of Coal. Then, group [B] contains the two variables for fuel modification of energy production as

${ }^{1}$ European Union Allowance. 
follows: Var.04: Clean Spark Spread and Var.05: Clean Dark Spread. As for group [C], we have the two structural movement variables, Var.06: Dummy Structural Movement and Var.08: The impact of economic activity and the financial crisis on electricity production - Variations SBF250. Finally, the group [D] is dedicated to the three atmospheric variables, Var.09: Extremely Cold Dummy, Var.10: Extremely Hot Dummy and Var.11: Seasonal Normal Variations. According to our econometric analyzes of the first period of the EU ETS, we have chosen ten (10) variables. In this respect, we can assume that six (06) explanatory variables have a positive predicted sign and four (04) explanatory variables have a negative predicted sign.

\section{- The variables of the second period 2008 - 2010}

The explanatory variables for the second period, known as the commitment phase, of the Kyoto Protocol (PK) of the European Union Emissions Trading Scheme (EU ETS) are also presented in four (4) groups of explanatory variables (Edmonds, Mac Cracken, Sands and Kim, 1998). The group [A] contains the variables of primary energies namely Var.01: Variation of Brent price, Var.02: Variation of Gas price and Var.03: Variation of the price of Coal. Then, group $[\mathbf{B}]$ contains the two fuel modification variables of energy production as follows: Var.04: Clean Spark Spread and Var.05: Clean Dark Spread. Concerning group [C], we are able to show the two variables of the structural movement, Var.07: Dummy Structural Movement and Var.08: The impact of economic activity and the financial crisis on electricity production - Variations SBF250. Lastly, the group [D] contains to three (3) atmospheric variables, Var.09: Extremely Cold Dummy, Var.10: Extremely Hot Dummy and Var.11: Seasonal Normal Variations. To summarize, we selected for the second period of the EU ETS, ten (10) variables as the first period of the EU ETS. Nevertheless, we replaced the variable Dummy Structural Movement by the variable Dummy Crisis of Subprimes. For this purpose, we can conclude that six (06) explanatory variables have a positive predicted sign and four (04) explanatory variables have a negative predicted sign.

\section{II.2 Specification of the EU ETS Econometric Model}

Economically speaking, our study aims to show the performance of the strategies of the actors of the EU ETS via the EUA price. In order to achieve this, we can retain a multiple linear model (multiple regression) as the theory formalizes it, with the introduction of two (2) categories of variables: the endogenous variable and the several exogenous variables. « The general linear model is a generalization of the simple regression model in which several explanatory variables $»{ }^{1}$

$Y_{t}=\beta_{0}+\beta_{1} X_{1 t}+\beta_{2} X_{2 t}+\ldots+\beta_{k} X_{k t}+\varepsilon_{t} \operatorname{pour} t=1, \ldots ., n \quad(\text { II. } 2.1)^{2}$

«The parameter $\beta_{\mathrm{i}}$ is called partial regression coefficient, it measures the variation of $Y$ when $X_{i}$ increases by one unit and the other explanatory variables are kept constant. $\varepsilon$ represents the random error, it is unobservable and includes both measurement errors on the observed values of $Y$ and all other explanatory factors not taken into account in the model» (Translated. Elmarhoum, 2013, p. 13).

The multiple regression aims at explaining a dependent variable $Y$ and $p$ explanatory variables $X_{1}, X_{2}, X_{3}, \ldots$, $X_{p}(p>1)$. Then, if this relationship is confirmed, evaluate its intensity. To determine the variables that influence the performance of EU ETS stakeholders' strategies via the EUA price, we adopted the formulation and model that we want to estimate, as follows:

$$
\text { PERF } E U A_{i, t}=\alpha W_{i, t}+\beta X_{i, t}+\chi Z_{i, t}+\delta Y_{i, t}+\varepsilon_{i, t}(\text { II.2.2 })^{3}
$$

To be clear, our model includes four (4) groups of addressable variables for action on the EU ETS Stakeholder Strategy Performance via the EUA price ( PERF EUA $A_{i, t}$ ) and a random variable (error term), as follows:

$W_{i, t}$ : Variables of primary energies (Group A)

$X_{i, t}$ Fuel Modification Variables for Energy Production (Group B)

$Z_{i, t} \quad$ Variables of structural movement (Group C)

\footnotetext{
${ }^{1}$ Adapted and translated. BOURBONNAIS, Régis. Econométrie : manuel et exercices corrigés, 47.

${ }^{2}$ Loc. cit.s

${ }^{3} \mathrm{t}=1, \ldots, 94$ with $\mathrm{i}=$ Phase I with $\mathrm{t}=1, \ldots, 122$ avec $\mathrm{i}=$ Phase II.
} 
Financial Markets, Institutions and Risks, Volume 3, Issue 1, 2019

ISSN (online) - 2521-1242 ISSN (print) - 2521-1250

$Y_{i, t}$ Atmospheric variables (Group D)

$\varepsilon_{i, t}$ Random variable (error term), following a normal distribution $N=\left(0, \delta^{2}\right)$

\section{Results of the econometric analysis of the EU ETS}

We present here the analysis and validation of the results of our econometric model for phase I and phase II of the European Union Emissions Trading Scheme.

III.1 Analysis and validation of the results of the econometric model of Phase I EU ETS.

Our objective for Phase I of the European Union Emissions Trading Scheme (EU ETS) is to test the adjacent hypothesis, namely:

- Adjacent research hypothesis $\mathbf{n}^{\circ} 1-1$ : The performance of the Carbon Finance Strategy for Sustainable Finance is influenced by the integration of information on $\mathrm{CO} 2$ emissions during Phase I of the EU ETS.

Analysis of the data in this phase $\mathrm{I}^{1}$ of the European Union Emissions Trading Scheme (EU ETS) allowed us to compare our econometric results and the state of play that we conducted above (Ellerman and Montero, 2007). According to the econometric results ${ }^{2}$, the analysis of the coefficients « $\mathbf{R}^{2}$ ou $\mathbf{R}$-squared $»$ and « $\mathbf{R}^{2}$ adjusted » or « Adjusted R-squared » are different from the results of the multiple regression of phase I of the EU ETS. Indeed, we have $\mathbf{R}^{\mathbf{2}}$ or $\mathbf{R}$-squared $=\mathbf{0 . 3 5 5 3 5 6}$, Therefore the variations of the independent variables account for $35.53 \%$ of the price performance of the EUA. The objective is to show the correlations between the price variations of the EUA and the variations of the other variables.

To conclude this point in Phase I of the EU ETS, we identified four (4) types of determinants explaining the EUA price:

1. the first determinant "Changes in the price of gas (Gas)" [Var. 02] (EUA market regulatory information);

2. the second determinant "Changes in the price of coal (Coal)" [Var. 03];

3. the third determinant "Clean Dark Spread (CDS)" [Var. 05];

4. and in the end "Seasonal Normal Variations (VNS)" [Var. 11].

In this respect, we have attempted to show econometrically using multiple regression that changes in the price of carbon (EUA) react to changes in primary energy prices (mainly natural gas) during the 2005-2007 test period. At the $\mathbf{5 \%}$ level of significance, we can say that there is a significant relationship between the performance of the Carbon Finance strategy for sustainable finance. This relationship is influenced by the integration of information on $\mathrm{CO} 2$ emissions during Phase I. Ultimately, this analysis indicates that our adjacent research hypothesis $n^{\circ} 1-1$ is thus verified. ${ }^{3}$

III.2 Analysis and validation of the results of the econometric model of Phase II EU ETS.

The objective for Phase II ${ }^{4}$ of the European Union Emissions Trading Scheme (EU ETS) is to test the second adjacent hypothesis, namely:

- Adjacent research hypothesis n¹-2: The performance of the Carbon Finance Strategy for Sustainable Finance is affected by the subprime crisis during Phase II of the EU ETS. The analysis of this phase of the European Union Emissions Trading Scheme (EU ETS) has allowed us to compare our econometric results and the inventory we conducted previously. Referring to our econometric results ${ }^{5}$, the analysis of the coefficients « $\mathbf{R}^{\mathbf{2}}$ or $\mathbf{R}$-squared » et « $\mathbf{R}^{\mathbf{2}}$ adjusted » or « Adjusted $\mathbf{R}$-squared » are different from the results of the multiple regression of phase II of the EU ETS. Indeed, we have $\mathbf{R}^{\mathbf{2}}$ ou $\mathbf{R}$-squared $=\mathbf{0 . 8 4 6 1 1 1}$, therefore the variations of the independent variables explain $\mathbf{8 4 , 6 1 \%}$ Of the price performance of the UAE. The objective is to show the correlations between the price variations of the EUA and the variations of the other variables.

To conclude this point in phase II of the EU ETS, we identified five (5) types of determinants explaining the

\footnotetext{
${ }^{1}$ Bourgeois (2010) is the source of data for period I of the EU ETS.

${ }^{2}$ Econometric results provided by the Eviews software version 7.2.

${ }^{3}$ Fisher's statistic (F-test) allows us to validate our model. By consulting F tabulated (theoretical or critical) with the degrees of freedom of $5 \%$ and the number of observations; we find the tabulated $\mathrm{F}$ (theoretical or critical) which is equal to 2,04.

${ }^{4}$ Bourgeois (2010) is the source of data for period I of the EU ETS.

${ }^{5}$ Econometric results provided by the Eviews software version 7.2.
} 
EUA price:

1. The First Determinant "Variations In The Price Of Brent (Brent)" [Var. 01];

2. The Second Determinant "Changes in the price of coal (Coal)" [Var. 03];

3. the third determinant the variable "The impact of economic activity and the financial crisis on the production of electricity (SBF)" [Var. 08] ;

4. The fourth determinant is "Extremely Hot Dummy (DEC)" [Var. 10];

5. Finally, the last determinant "Seasonal Normal Variations (VNS)" [Var. 11].

In this regard, we have attempted to show econometrically using multiple regression that carbon price changes (EUA) respond to the impact of the subprime crisis during period II: 2008-2010. At the 5\% significance level we can say that there is a significant relationship between the performance of the Carbon Finance Strategy for Sustainable Finance is influenced by the Subprime crisis during Phase II. Ultimately, this analysis indicates that our adjacent research hypothesis $\mathbf{n}^{\circ} \mathbf{1 - 2}$ is thus verified. ${ }^{1}$

\section{Conclusion and future recommendations: The development of «Finance limiting global warming to $2^{\circ} \mathrm{C}$ » difficult but essential}

Carbon Finance will have consequences for the various economic actors, directly for industrial activities and indirectly for the rest of the socio-economic system. According to the literature, market mechanisms have led to the emergence of a carbon price signal, which companies must incorporate into their strategies in order to optimize their reductions in GHG emissions (Nordhaus, 1991). The interest for the company is to understand the ins and outs of Carbon Finance and to make the best use of allocated quotas in order to optimize their economic, financial and environmental performance. Thus, our central question of our research was formulated in the following way:

"What are the responsible issues and sustainable opportunities for the adoption of carbon finance for EU ETS companies for the development of a "2 ${ }^{\circ} \mathrm{C}$ Finance"? ».

In practice, several determinants of $\mathrm{CO} 2$ prices (EUA) exist to promote the resilience of Carbon Finance, which can be characterized by the price of carbon, primary energy prices: oil, natural gas and coal, Clean Dark Spread, The Clean Spark Spread and the Switch Price, the atmospheric variables and the SBF250 and the Subprime crisis. Unlike solutions that are inflexible or irreversible, that increase Climate Change or reduce the incentive to adapt to Carbon Finance would be poorly adopted (Springer, 2003).

The mechanisms of Carbon Finance have a prominent place for the realization of the Sustainable Development (SD) agendas for Carbon Finance to become «Finance $2^{\circ} \mathrm{C}$ ». In these circumstances, not including the anticipation of Climate Change (CC) and the adoption of Carbon Finance (especially the $\mathrm{CO} 2$ exchange system) will increase the risk of making our existence vulnerable to uncertainties while eliminating the actions and carbon transactions available to Sustainable Finance and Sustainable Development (SD). It seems very useful to inject less GHGs in absolute terms, but the real challenge is to reduce the GHGs to a threshold that limits the rise in temperature to $2^{\circ} \mathrm{C}$ (Toth, 1999). To carry out our study, we decided to treat each period of the EU ETS in a different way according to their specificities and the academic work already carried out. In addition to the results of the econometric tool itself and their analysis, the process of sensitizing the industrial players and refocusing reflection on their own interest, that maximizing profitability (or avoid reducing profitability) a project to exchange EU ETS CO2 allowances for current and future climate change.

\section{References}

1. Alberola, E., Chevallier, J., Cheze, B. (2009). The EU Emissions Trading Scheme: the effects of industrial production and $\mathrm{CO}^{2}$ emissions on European carbon prices, Economie Internationale, 116, 93-126.

2. Alberola, E., Chevallier, J., Cheze B. (2009). Emissions compliances and carbon prices under the EU ETS: a country specific analysis of industrial sectors, Journal of Policy Modelling, 31, 446-462.

3. Alberola, E., Chevallier, J. (2009). European carbon prices and banking restrictions: evidence from Phase I (2005-2007), The Energy Journal, 30(3), 51-79.

\footnotetext{
${ }^{1}$ Fisher's statistic (F-test) allows us to validate our model. By consulting F tabulated (theoretical or critical) with the degrees of freedom of $5 \%$ and the number of observation; we find the tabulated $\mathrm{F}$ (theoretical or critical) which is equal to 2,01.
} 
Financial Markets, Institutions and Risks, Volume 3, Issue 1, 2019

ISSN (online) - 2521-1242 ISSN (print) - 2521-1250

4. Alberola, E., Chevallier, J., Cheze B. (2008). Price drivers and structural breaks in European carbon prices 2005-2007, Energy policy, 32(2), 787-797.

5. Bokenkamp, K., La Flash V., Bachrach Wang D. (2005). Hedging carbon risk: protecting customers and shareholders from the financial risk associated with carbon dioxide emissions, The Electricity Journal, 18(6), $11-24$.

6. Bonn. (2002). A guide to the climate change convention process, UNFCCC working paper, $49 \mathrm{p}$.

7. Bourbonnais, R. (2011). Econométrie: manuel et exercices corrigés, Dunod.

8. Bourgeois, L. (2010). Entreprises et finance carbone: enjeux et opportunités, Mémoire de recherche soutenu à l'Ecole Supérieure des Sciences Sociales d'Angers, juillet 2010, 75.

9. Bureau, D. (2010). A propos du rapport du PRADA: l'économie de la régulation des marchés du CO2 », Références économiques: Conseil économique pour le développement durable $\mathrm{n}^{\circ} .10$.

10. Broome, J. (1992). Counting the costs of global warming, White House Press.

11. Bunn, D., Fezzi, C. (2007). Interaction of European carbon trading and energy prices, Fondazione Eni Enrico Mattei working paper, 123, 25 p.

12. Capoor, K., Ambrosi, P. (2009). State and trends of the carbon market 2009, World Bank working paper, 80 p.

13. Capoor, K., Ambrosi P. (2007). State and trends of the carbon market 2007, World Bank working paper, 52 p.

14. Chevallier, J. (2012). Econometric Analysis of Carbon Markets: the European Union Emissions Trading Scheme and the Clean Development Mechanism, Springer.

15. Chevallier, J. (2009). Carbon futures and macroeconomic risk factors: a view from the EU ETS, Energy Economics, 31, 614-625.

16. Chevallier, J. (2008). Les règles de fonctionnement du marché européen du carbone (2005-2007) : le rôle du stockage et de l'emprunt de quotas, les fondamentaux du prix et les stratégies de gestion des risques, Thèse de Doctorat soutenue à l'Université Paris X Nanterre, le 05 novembre 2008, 301 pages.

17. Christiansen, A., Arvanitakis, A., Tangen K., Hasselknippe H. (2005). Price determinants in the EU Emissions Trading Scheme, Climate Policy, 5, 15- 30.

18. Christiansen, A., Arvanitakis, A. (2004). What determines the price of carbon in the European Union? European Climate Exchange working paper, $40 \mathrm{p}$.

19. Convery, F. J., Rechmond, L. (2007). Market and price developments in the European Union Emissions Trading Scheme, Review of Environmental Economics and Policy, 1, 88-111.

20. Criqui, P., Kouvaritakis, N. (2000). World energy projections to 2030. International Journal of Global Energy Issues, 14, 116-136.

21. Criqui, P., Viguier, L. (2000). Kyoto and technology at world level: costs of CO2 reduction under flexibility mechanisms and technical progress, International Journal of Global Energy Issues, 14, 155-168.

22. Criqui, P., Mima S., Viguier, L. (1999). Marginal abatement costs of $\mathrm{CO}^{2}$ emission reductions, geographical flexibility and concrete ceilings: an assessment using the POLES model, Energy Policy, 27, 585601.

23. Delarue, E., D'haeseleet, W. (2007). Price determination of ETS allowances through the switching level of coal and gas in the power sector, International Journal of Energy Research, 31, 1001-1015.

24. Edmonds, J., Mac Cracken, C., Sands, R., Kim, S. (1998). The economics of the Kyoto protocol, The Energy Journal, 25-72.

25. Ellerman, A. D., Montero J. P. (2007). The efficiency and robustness of allowance banking in the US Acid Rain Program, The Energy Journal, 28, 205-233.

26. Ellerman, A. D., Buchner B. K. (2008). Over-allocation or abatement? A preliminary analysis of the EU ETS based on the 2005-2006 emissions data, Environmental and Resource Economics, 41, 267-287.

27. Ellerman, A. D., Buchner B. K. (2007). The European Union Emissions Trading Scheme: origins, allocation and early results, Review of Environmental Economics and Policy, 1, 66-87. 
28. Ellerman, D., Jacoby H., Decaux A. (1998). The effects on developing countries of the Kyoto protocol and $\mathrm{CO}^{2}$ emissions trading, MIT report.

29. Elmarhoum, A. (2013). Analyse des données, édition co-éditée par IGA Ecole de Management et TOUBKAL.

30. Fama, E. (1965). The behavior of stocks market prices, Journal of Business, 38, 34-105.

31. Gray, R., Bebbington J., Walters D. (1993). Accounting for the environment, Paul Chapman in association with the Chartered Association of Certified Accountants.

32. Hardin, G. (1968). The tragedy of commons, Science, 162, 1243-1248.

33. Keppler, J. (2007). Causality and cointegration between Energy consumption and economic growth in Developing Countries, in Keppler J. et al. The Econometrics of Energy Systems.Palgrave.

34. Klepper, G., Peterson S. (2006). Emissions trading, CDM, JI and more: the climate strategy of the EU», The Energy Journal, 27(2), $26 \mathrm{p}$.

35. Le Comte, D., Warren H. E. (1981). Modelling the impact of summer temperatures on national electricity consumption, Journal of Applied Methodology, 22, 1415-1419.

36. Larson, D., Ambrosi, P., Dinar, A., Rahman, S. M., Entler, R. (2008). Carbon markets, Institutions, Policies and Research, (2008), Policy research working paper, World Bank, 4761, 72 p.

37. Lee, J., Strazicich, M. C. (2003). Minimum LM unit root test with two structural breaks, Review of Economics and Statistics, 85, 1082-1089.

38. Li, X., Sailor D. J. (1995). Electricity use sensitivity to climate and climate change, World Resource Review, 7, 334-346.

39. Lowrey, C. (2006). A changing environment, FOW Energy, 24-26.

40. Mansanet-Bataller, M., Pardo, A., Valor, E. (2007). $\mathrm{CO}^{2}$ prices, energy and weather, (2007), The Energy Journal, 28(3), 73-92.

41. Mendelsohn, R. (1998). Climate change damages, Economics and Policy Issues in Climate Change, pp. 219-236.

42. Nordhaus, W. D. (1991). To slow or not to slow: the economics of the greenhouse effect, Economic Journal, 101, 920-937.

43. Pearce, D., Atkinson, G., Mourato, S. (2006). Cost-benefit analysis and the environment, OECD publication, $318 \mathrm{pp}$.

44. Peirson, J., Henley, A. (1994). Electricity load and temperature, issues in dynamic specification », Energy Economics, 16, 235-243.

45. Portney, P. R. (1994). Applicability of cost-benefit analysis to climate change, Economics and Policy Issues in Climate Change, 111-127.

46. Reinaud, J. (2004). Emissions trading and its possible impacts on investment decisions in the power sector, International Energy Agency, 74 p.

47. Roll, R. (1994). Orange juice and weather, The American Economic Review, 74, 861-879.

48. Schennach, S. M. (2000). The economics of pollution permit banking in the context of Title IV of the 1990 Clean Air Act amendments, Journal of Environmental Economics and Management, 40, 189-210.

49. Springer, U. (2003). The market for tradable GHG permits under the Kyoto Protocol: a survey of model studies, Energy Economics, 25, 527-551.

50. Toth, F. L. (1999). Integrated assessments of climate change policy: intergenerational equity and discounting, FEEM Working paper, 52-99.

51. Wettestad, J., Skjaerseth, J. (2007). Implementing EU Emissions Trading: Success or Failure? Paper presented at the annual meeting of the International Studies Association 48th Annual Convention. 


\section{Appendix}

Table 1. The four groups of variables in the econometric study of the EU ETS

\begin{tabular}{|l|c|c|}
\hline PERF EUA ${ }_{i, t}$ & Performance of the strategies of EU ETS actors via the EUA price & $\begin{array}{c}\text { Groups } \\
\text { of variables }\end{array}$ \\
\hline$W_{i, t}$ & primary energies variables & Group A \\
\hline Brent $_{i, t}$ & Variation of Brent price & (Var. 01) \\
\hline $\mathrm{Gas}_{\mathrm{i}, \mathrm{t}}$ & Variation of Gas price & (Var) \\
\hline $\mathrm{Coal}_{\mathrm{i}, \mathrm{t}}$ & Variation of Coal price & Group B \\
\hline$X_{i, t}$ & Fuel modification variables of energy production & (Var. 04) \\
\hline $\mathrm{CSS}_{\mathrm{i}, \mathrm{t}}$ & Clean Spark Spread & (Var. 05) \\
\hline $\mathrm{CDS}_{\mathrm{i}, \mathrm{t}}$ & Clean Dark Spread & Group C \\
\hline$Z_{i, t}$ & Structural movement variables & (Var. 06) \\
\hline $\mathrm{DMS}_{\mathrm{i}, \mathrm{t}}$ & Dummy Structural Movement for Phase I & (Var. 07) \\
\hline $\mathrm{DCS}_{\mathrm{i}, \mathrm{t}}$ & Dummy Subprime Crisis for Phase II & (Var. 08) \\
\hline $\mathrm{SBF}_{\mathrm{i}, \mathrm{t}}$ & Variations SBF 250 & Group D \\
\hline$Y_{i, t}$ & Atmospheric variables & (Var. 09) \\
\hline $\mathrm{DEF}_{\mathrm{i}, \mathrm{t}}$ & Extremely Cold Dummy & (Var. 10) \\
\hline $\mathrm{DEC}_{\mathrm{i}, \mathrm{t}}$ & Extremely Hot Dummy & (Var. 11) \\
\hline $\mathrm{VNS}_{\mathrm{i}, \mathrm{t}}$ & Seasonal Normal Variations & Term of error \\
\hline$\varepsilon_{i, t}$ & Random variable (error term), following a normal distribution $N=\left(0, \delta^{2}\right)$ & \\
\hline
\end{tabular}

Table 2. Results of the stationarity tests of the variables of the model of phase I EU ETS

\begin{tabular}{|l|c|c|c|c|c|c|}
\hline & $\begin{array}{c}\text { Without constant } \\
\text { term or trend }\end{array}$ & $\begin{array}{c}\text { With constant } \\
\text { term }\end{array}$ & With trend & $\begin{array}{c}\text { With constant } \\
\text { term and trend }\end{array}$ & First Difference & Conclusion \\
\hline Brent & $\mathrm{S}$ & $\mathrm{S}$ & $\mathrm{S}$ & $\mathrm{NS}$ & $\mathrm{NS}$ & RVL \\
\hline CDS & $\mathrm{S}$ & $\mathrm{S}$ & $\mathrm{NS}$ & $\mathrm{NS}$ & $\mathrm{NS}$ & RVL \\
\hline Coal & $\mathrm{S}$ & $\mathrm{S}$ & $\mathrm{S}$ & $\mathrm{S}$ & $\mathrm{NS}$ & RVL \\
\hline CSS & $\mathrm{S}$ & $\mathrm{S}$ & $\mathrm{S}$ & $\mathrm{S}$ & $\mathrm{NS}$ & RVL \\
\hline DEC & $\mathrm{S}$ & $\mathrm{S}$ & $\mathrm{S}$ & $\mathrm{S}$ & $\mathrm{S}$ & RVL \\
\hline DEF & $\mathrm{S}$ & $\mathrm{S}$ & $\mathrm{NS}$ & $\mathrm{NS}$ & $\mathrm{NS}$ & RVL \\
\hline GAS & $\mathrm{S}$ & $\mathrm{S}$ & $\mathrm{S}$ & $\mathrm{NS}$ & $\mathrm{NS}$ & RVL \\
\hline SBF & $\mathrm{S}$ & $\mathrm{S}$ & $\mathrm{S}$ & $\mathrm{S}$ & $\mathrm{NS}$ & RVL \\
\hline VNS & $\mathrm{S}$ & $\mathrm{S}$ & $\mathrm{S}$ & $\mathrm{NS}$ & $\mathrm{NS}$ & RVL \\
\hline
\end{tabular}

N.B: $\mathrm{S}=$ Stationary; $\mathrm{NS}=$ No- Stationary; $\mathrm{RVL}=$ Retain the Variable in Level

Table 3. Results of the stationarity tests of the variables of the model of phase II EU ETS

\begin{tabular}{|l|c|c|c|c|c|c|}
\hline & $\begin{array}{c}\text { Without constant } \\
\text { term or trend }\end{array}$ & $\begin{array}{c}\text { With constant } \\
\text { term }\end{array}$ & With trend & $\begin{array}{c}\text { With constant } \\
\text { term and trend }\end{array}$ & First Difference & Conclusion \\
\hline Brent & $\mathrm{S}$ & $\mathrm{S}$ & $\mathrm{S}$ & $\mathrm{NS}$ & $\mathrm{NS}$ & $\mathrm{RVL}$ \\
\hline CDS & $\mathrm{S}$ & $\mathrm{S}$ & $\mathrm{NS}$ & $\mathrm{NS}$ & $\mathrm{S}$ & $\mathrm{R}$ \\
\hline Coal & $\mathrm{S}$ & $\mathrm{S}$ & $\mathrm{S}$ & $\mathrm{S}$ & $\mathrm{S}$ & $\mathrm{R}$ \\
\hline CSS & $\mathrm{S}$ & $\mathrm{S}$ & $\mathrm{S}$ & $\mathrm{S}$ & $\mathrm{S}$ & $\mathrm{R}$ \\
\hline DEC & $\mathrm{S}$ & $\mathrm{S}$ & $\mathrm{S}$ & $\mathrm{S}$ & $\mathrm{NS}$ & $\mathrm{R}$ \\
\hline DEF & $\mathrm{S}$ & $\mathrm{S}$ & $\mathrm{S}$ & $\mathrm{NS}$ & $\mathrm{S}$ & $\mathrm{R}$ \\
\hline GAS & $\mathrm{S}$ & $\mathrm{S}$ & $\mathrm{S}$ & $\mathrm{S}$ & $\mathrm{NS}$ & $\mathrm{R}$ \\
\hline SBF & $\mathrm{S}$ & $\mathrm{S}$ & $\mathrm{S}$ & $\mathrm{S}$ & $\mathrm{N}$ & $\mathrm{R}$ \\
\hline VNS & $\mathrm{S}$ & $\mathrm{S}$ & $\mathrm{S}$ & $\mathrm{S}$ & $\mathrm{S}$ & $\mathrm{R}$ \\
\hline
\end{tabular}

N.B : $\quad \mathrm{S}=$ Stationary $; \quad \mathrm{NS}=$ No- Stationary $\quad ; \mathrm{RVL}=$ Retain the Variable in Level

Table 4. Results of the multiple regression of the phase I of the EU ETS under Eviews

\begin{tabular}{|c|c|c|c|c|}
\hline \multicolumn{5}{|c|}{ Dependent Variable: PERF_EUA } \\
\hline \multicolumn{5}{|c|}{ Method: Least Squares } \\
\hline \multicolumn{5}{|l|}{ Date: 03/29/15 Time: $15: 20$} \\
\hline \multicolumn{5}{|l|}{ Sample: 194} \\
\hline \multicolumn{5}{|c|}{ Included observations: 94 period I EU ETS } \\
\hline \begin{tabular}{|c|} 
Variables \\
\end{tabular} & Coefficient & Std. Error & $\mathrm{t}$-Statistic & Prob. \\
\hline & -0.014148 & 0.007521 & -1.881095 & 0.0634 \\
\hline BRENT & -0.222378 & 0.214916 & -1.034717 & 0.3038 \\
\hline CDS & -0.296163 & 0.050686 & -5.843100 & 0.0000 \\
\hline COAL & -0.716404 & 0.233243 & -3.071490 & 0.0029 \\
\hline CSS & 0.014616 & 0.012034 & 1.214549 & 0.2279 \\
\hline DEC & -0.081566 & 0.052840 & -1.543649 & 0.1264 \\
\hline
\end{tabular}


Financial Markets, Institutions and Risks, Volume 3, Issue 1, 2019

ISSN (online) - 2521-1242 ISSN (print) - 2521-1250

Table 4 (cont.). Results of the multiple regression of the phase I of the EU ETS under Eviews

\begin{tabular}{|l|c|c|c|c|}
\hline DEF & -0.016117 & 0.029989 & -0.537439 & 0.5924 \\
\hline GAS & 0.169822 & 0.062405 & 2.721279 & 0.0079 \\
\hline SBF & -0.737676 & 0.372122 & -1.982347 & 0.0507 \\
\hline VNS & -0.000931 & 0.000336 & -2.770596 & 0.0069 \\
\hline R-squared & 0.417741 & Mean dependent var & -0.008830 \\
\hline Adjusted R-squared & 0.355356 & S.D. dependent var & 0.062128 \\
\hline S.E. of regression (SER) & 0.049883 & Akaike info criterion & -3.058005 \\
\hline Sum squared resid & 0.209014 & Schwarz criterion & -2.787441 \\
\hline Log likelihood & 153.7262 & Hannan-Quinn criter. & -2.948717 \\
\hline F-statistic & 6.696190 & Durbin-Watson stat & 2.138006 \\
\hline Prob(F-statistic) & 0.000000 & & & \\
\hline
\end{tabular}

Table 5. Results of the multiple regression of the phase I of the EU ETS under Eviews

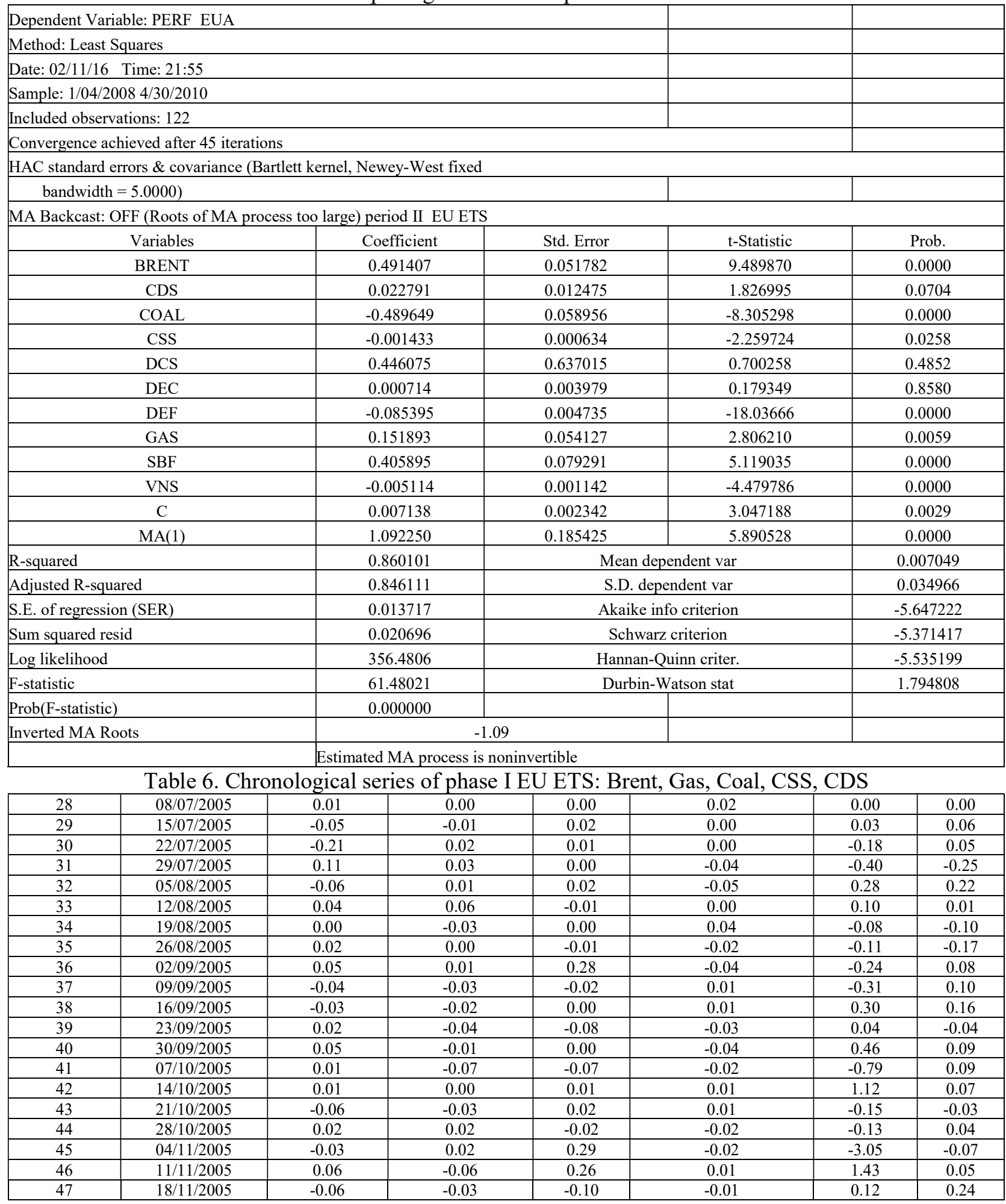


Financial Markets, Institutions and Risks, Volume 3, Issue 1, 2019

ISSN (online) - 2521-1242 ISSN (print) - 2521-1250

Table 6 (cont.). Chronological series of phase I EU ETS: Brent, Gas, Coal, CSS, CDS

\begin{tabular}{|l|c|c|c|c|c|c|c|}
\hline 48 & $25 / 11 / 2005$ & -0.08 & -0.01 & 0.06 & 0.02 & 0.81 & 0.24 \\
\hline 49 & $02 / 12 / 2005$ & 0.04 & 0.04 & 0.17 & 0.02 & 0.10 & 0.11 \\
\hline 50 & $09 / 12 / 2005$ & -0.04 & -0.01 & -0.19 & 0.01 & -0.11 & 0.01 \\
\hline 51 & $16 / 12 / 2005$ & 0.00 & -0.03 & -0.02 & -0.05 & -0.33 & 0.19 \\
\hline 52 & $23 / 12 / 2005$ & -0.03 & 0.02 & -0.05 & 0.02 & -0.75 & 0.22 \\
\hline
\end{tabular}

Source: Données Thomson Reuters (Bourgeois. 2010).

Table 7. Chronological series of phase I EU ETS: DMS. SBF. DEF. DEC. VNS

\begin{tabular}{|c|c|c|c|c|c|c|c|}
\hline 28 & $08 / 07 / 2005$ & 0.01 & 0.00 & 0.00 & 0.00 & 0.00 & 1.46 \\
\hline 29 & $15 / 07 / 2005$ & -0.05 & 0.00 & 0.01 & 0.00 & 0.00 & 1.11 \\
\hline 30 & $22 / 07 / 2005$ & -0.21 & 0.00 & 0.02 & 0.00 & 0.00 & -2.63 \\
\hline 31 & $29 / 07 / 2005$ & 0.11 & 0.00 & 0.01 & 0.00 & 0.00 & -4.02 \\
\hline 32 & $05 / 08 / 2005$ & -0.06 & 0.00 & 0.01 & 0.00 & 0.00 & -4.42 \\
\hline 33 & $12 / 08 / 2005$ & 0.04 & 0.00 & -0.01 & 0.00 & 0.00 & -3.64 \\
\hline 34 & $19 / 08 / 2005$ & 0.00 & 0.00 & 0.01 & 0.00 & 0.00 & -3.06 \\
\hline 35 & $26 / 08 / 2005$ & 0.02 & 0.00 & 0.00 & 0.00 & 0.00 & -1.87 \\
\hline 36 & $02 / 09 / 2005$ & 0.05 & 0.00 & -0.03 & 0.00 & 0.00 & -5.02 \\
\hline 37 & $09 / 09 / 2005$ & -0.04 & 0.00 & 0.02 & 0.00 & 0.00 & -8.47 \\
\hline 38 & $16 / 09 / 2005$ & -0.03 & 0.00 & 0.02 & 0.00 & 0.00 & -9.11 \\
\hline 39 & $23 / 09 / 2005$ & 0.02 & 0.00 & 0.01 & 0.00 & 0.00 & -8.28 \\
\hline 40 & $30 / 09 / 2005$ & 0.05 & 0.00 & -0.01 & 0.00 & 0.00 & -6.64 \\
\hline 41 & $07 / 10 / 2005$ & 0.01 & 0.00 & 0.03 & 0.00 & 0.00 & -15.79 \\
\hline 42 & $14 / 10 / 2005$ & 0.01 & 0.00 & -0.02 & 0.00 & 0.00 & -14.72 \\
\hline 43 & $21 / 10 / 2005$ & -0.06 & 0.00 & -0.01 & 0.00 & 0.00 & -14.77 \\
\hline 44 & $28 / 10 / 2005$ & 0.02 & 0.00 & -0.03 & 0.00 & 0.00 & -16.00 \\
\hline 45 & $04 / 11 / 2005$ & -0.03 & 0.00 & -0.01 & 0.00 & 1.00 & -24.76 \\
\hline 46 & $11 / 11 / 2005$ & 0.06 & 0.00 & 0.04 & 0.00 & 0.00 & -35.42 \\
\hline 47 & $18 / 11 / 2005$ & -0.06 & 0.00 & 0.01 & 0.00 & 0.00 & -41.81 \\
\hline 48 & $25 / 11 / 2005$ & -0.08 & 0.00 & 0.01 & 1.00 & 0.00 & -62.23 \\
\hline 49 & $02 / 12 / 2005$ & 0.04 & 0.00 & 0.01 & 1.00 & 0.00 & -68.69 \\
\hline 50 & $09 / 12 / 2005$ & -0.04 & 0.00 & 0.01 & 0.00 & 0.00 & -65.15 \\
\hline 51 & $16 / 12 / 2005$ & 0.00 & 0.00 & 0.00 & 0.00 & 0.00 & -60.36 \\
\hline 52 & $23 / 12 / 2005$ & -0.03 & 0.00 & 0.01 & 0.00 & 0.00 & -52.57 \\
\hline
\end{tabular}

Source: Données Thomson Reuters (Bourgeois. 2010).

Table 8. Chronological series of phase II EU ETS: BRENT. GAS. COAL. CSS. CDS

\begin{tabular}{|l|c|c|c|c|c|c|c|}
\hline \multicolumn{1}{|c|}{ Week } & Date & EUA & BRENT & GAS & COAL & CSS & CDS \\
\hline 1 & $04 / 01 / 2008$ & 0.05 & 0.03 & 0.01 & -0.03 & 0.00 & 0.00 \\
\hline 2 & $11 / 01 / 2008$ & -0.02 & -0.04 & 0.04 & 0.01 & -0.20 & -0.09 \\
\hline 3 & $18 / 01 / 2008$ & -0.05 & -0.04 & -0.06 & 0.01 & -0.04 & -0.24 \\
\hline 4 & $25 / 01 / 2008$ & 0.01 & 0.04 & 0.01 & -0.02 & -0.32 & -0.07 \\
\hline 5 & $01 / 02 / 2008$ & -0.07 & -0.02 & -0.08 & 0.06 & 0.19 & -0.22 \\
\hline 6 & $08 / 02 / 2008$ & 0.06 & 0.01 & 0.04 & 0.00 & -0.43 & -0.21 \\
\hline 7 & $15 / 02 / 2008$ & 0.04 & 0.01 & 0.00 & 0.01 & -0.18 & -0.22 \\
\hline 8 & $22 / 02 / 2008$ & 0.03 & 0.02 & 0.00 & -0.03 & 0.43 & 0.21 \\
\hline 9 & $29 / 02 / 2008$ & -0.01 & 0.02 & 0.05 & -0.01 & -0.24 & 0.04 \\
\hline 10 & $07 / 03 / 2008$ & 0.01 & 0.02 & 0.01 & -0.03 & 0.05 & 0.01 \\
\hline 11 & $14 / 03 / 2008$ & 0.02 & 0.03 & 0.00 & -0.03 & 0.18 & 0.14 \\
\hline 12 & $21 / 03 / 2008$ & 0.03 & -0.01 & 0.00 & 0.00 & -0.02 & 0.00 \\
\hline 13 & $28 / 03 / 2008$ & -0.01 & 0.04 & 0.00 & -0.03 & -0.02 & 0.03 \\
\hline 14 & $04 / 04 / 2008$ & 0.07 & 0.05 & 0.05 & -0.09 & -0.92 & -0.37 \\
\hline 15 & $11 / 04 / 2008$ & 0.04 & 0.02 & 0.02 & 0.01 & 3.48 & 0.08 \\
\hline 16 & $18 / 04 / 2008$ & -0.02 & 0.04 & 0.00 & 0.03 & -0.37 & -0.04 \\
\hline 17 & $25 / 04 / 2008$ & -0.02 & 0.02 & 0.09 & 0.02 & -1.09 & 0.02 \\
\hline 18 & $02 / 05 / 2008$ & -0.03 & -0.02 & -0.06 & 0.06 & -5.15 & 0.24 \\
\hline 19 & $09 / 05 / 2008$ & 0.00 & 0.06 & -0.14 & 0.03 & 7.93 & 0.04 \\
\hline 20 & $16 / 05 / 2008$ & -0.02 & 0.02 & 0.01 & 0.02 & -0.12 & -0.02 \\
\hline 21 & $23 / 05 / 2008$ & 0.04 & 0.05 & -0.03 & 0.01 & 0.45 & -0.09 \\
\hline 22 & $30 / 05 / 2008$ & -0.01 & -0.03 & 0.03 & 0.02 & 0.39 & 0.44 \\
\hline 23 & $06 / 06 / 2008$ & 0.05 & 0.08 & 0.02 & 0.00 & -0.11 & 0.09 \\
\hline 24 & $13 / 06 / 2008$ & -0.02 & 0.00 & 0.05 & 0.05 & -0.17 & -0.05 \\
\hline 25 & $20 / 06 / 2008$ & 0.01 & 0.00 & 0.00 & 0.02 & 0.02 & -0.06 \\
\hline
\end{tabular}

Source: Données Thomson Reuters (Bourgeois, 2010).

Table 9. Chronological series of phase II EU ETS: DCF, SBF, DEF, DEC, VNS

\begin{tabular}{|l|c|c|c|c|c|c|c|}
\hline Week & Date & EUA & DCF & SBF & DEF & DEC & VNS \\
\hline 26 & $04 / 01 / 2008$ & 0.05 & 0.00 & 0.00 & 0.00 & 0.00 & -0.81 \\
\hline 27 & $11 / 01 / 2008$ & -0.02 & 0.00 & -0.05 & 0.00 & 0.00 & 2.48 \\
\hline 28 & $18 / 01 / 2008$ & -0.05 & 0.00 & -0.03 & 0.00 & 0.00 & 2.22 \\
\hline
\end{tabular}


Table 9 (cont.). Chronological series of phase II EU ETS: DCF, SBF, DEF, DEC, VNS

\begin{tabular}{|l|c|c|c|c|c|c|c|}
\hline 29 & $25 / 01 / 2008$ & 0.01 & 0.00 & 0.02 & 0.00 & 0.00 & 3.44 \\
\hline 30 & $01 / 02 / 2008$ & -0.07 & 0.00 & -0.05 & 0.00 & 0.00 & 1.94 \\
\hline 31 & $08 / 02 / 2008$ & 0.06 & 0.00 & 0.01 & 0.00 & 0.00 & 0.32 \\
\hline 32 & $15 / 02 / 2008$ & 0.04 & 0.00 & 0.01 & 0.00 & 0.00 & 0.40 \\
\hline 33 & $22 / 02 / 2008$ & 0.03 & 0.00 & -0.01 & 0.00 & 0.00 & 0.70 \\
\hline 34 & $29 / 02 / 2008$ & -0.01 & 0.00 & -0.03 & 0.00 & 1.00 & 3.96 \\
\hline 35 & $07 / 03 / 2008$ & 0.01 & 0.00 & -0.01 & 0.00 & 0.00 & 0.97 \\
\hline 36 & $14 / 03 / 2008$ & 0.02 & 0.00 & -0.02 & 0.00 & 0.00 & 1.49 \\
\hline 37 & $21 / 03 / 2008$ & 0.03 & 0.00 & 0.04 & 0.00 & 0.00 & -1.22 \\
\hline 38 & $28 / 03 / 2008$ & -0.01 & 0.00 & 0.04 & 1.00 & 0.00 & -3.64 \\
\hline 39 & $04 / 04 / 2008$ & 0.07 & 0.00 & -0.02 & 0.00 & 0.00 & 0.15 \\
\hline 40 & $11 / 04 / 2008$ & 0.04 & 0.00 & 0.03 & 0.00 & 0.00 & -2.01 \\
\hline 41 & $18 / 04 / 2008$ & -0.02 & 0.00 & 0.00 & 0.00 & 0.00 & -1.80 \\
\hline 42 & $25 / 04 / 2008$ & -0.02 & 0.00 & 0.02 & 0.00 & 0.00 & -0.59 \\
\hline 43 & $02 / 05 / 2008$ & -0.03 & 0.00 & -0.02 & 0.00 & 0.00 & -0.96 \\
\hline 44 & $09 / 05 / 2008$ & 0.00 & 0.00 & 0.02 & 0.00 & 0.00 & 1.14 \\
\hline 45 & $16 / 05 / 2008$ & -0.02 & 0.00 & -0.03 & 0.00 & 0.00 & 1.75 \\
\hline 46 & $23 / 05 / 2008$ & 0.04 & 0.00 & 0.02 & 0.00 & 0.00 & -1.65 \\
\hline 47 & $30 / 05 / 2008$ & -0.01 & 0.00 & -0.04 & 0.00 & 0.00 & 1.37 \\
\hline 48 & $06 / 06 / 2008$ & 0.05 & 0.00 & -0.02 & 0.00 & 0.00 & 0.57 \\
\hline 49 & $13 / 06 / 2008$ & -0.02 & 0.00 & -0.04 & 0.00 & 0.00 & -0.55 \\
\hline 50 & $20 / 06 / 2008$ & 0.01 & 0.00 & -0.03 & 0.00 & 0.00 & -2.36 \\
\hline
\end{tabular}

Source: Thomson Reuters Data (Bourgeois, 2010).

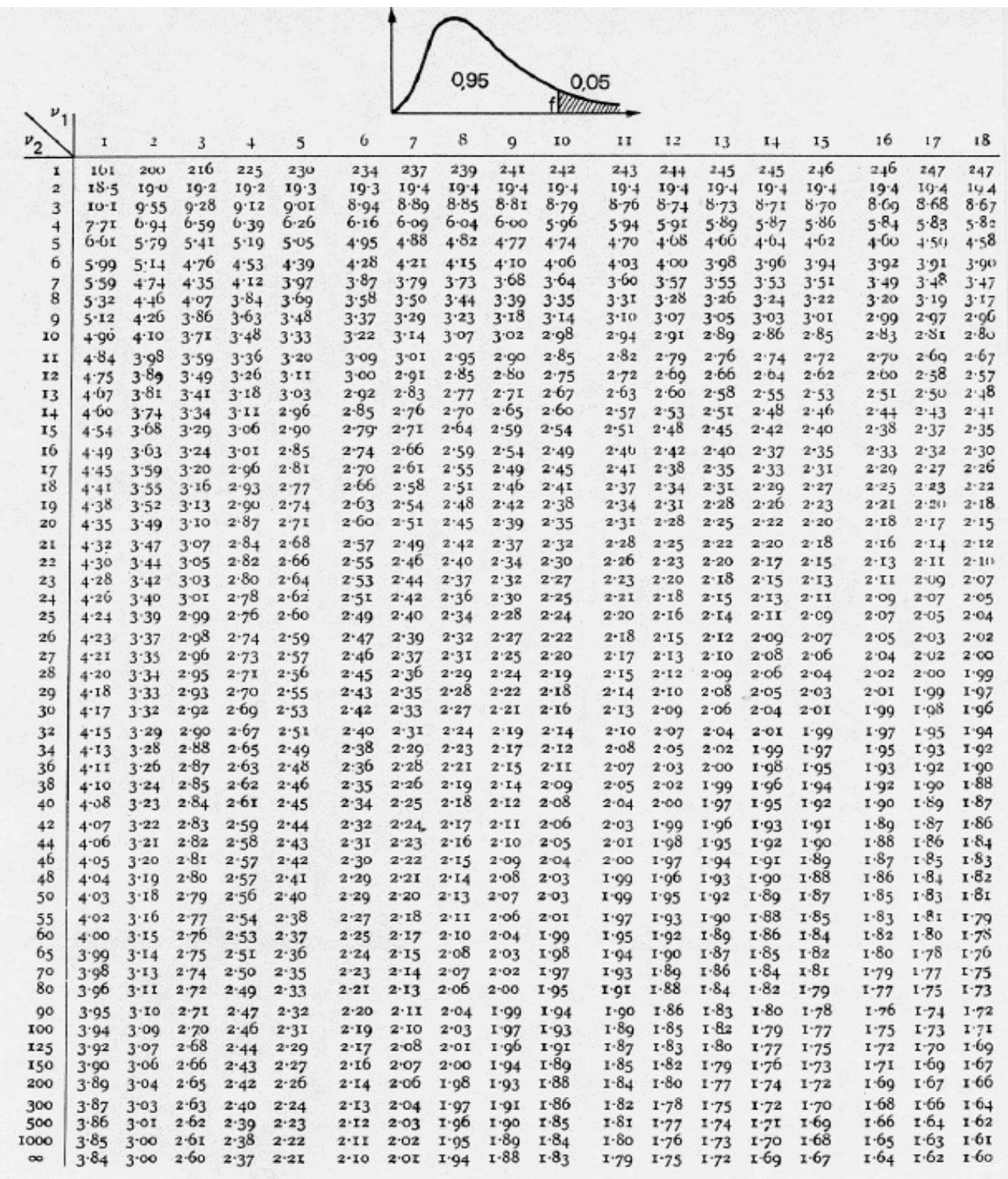

Figure 2. Fisher Variable.

Source:http://medecine-pharmacie.univ-fcomte.fr/download/ufr-smp/document/supports-de-cours-2014/paces-ue4---annexes.pdf 